Check for updates

Cite this: Mater. Adv., 2021, 2,5494

Received 22nd February 2021, Accepted 17th June 2021

DOI: 10.1039/d1ma00157d

rsc.li/materials-advances

\section{P-type cobaltite oxide spinels enable efficient electrocatalytic oxygen evolution reaction $\dagger$}

\author{
David Doppelbauer, ${ }^{\text {ab }}$ Abdalaziz Aljabour, ${ }^{a}$ Halime Coskun, ${ }^{a}$ He Sun, ${ }^{\text {ac }}$ \\ Markus Gusenbauer, ${ }^{\text {b }}$ Julia Lumetzberger, ${ }^{b}$ Daniel Primetzhofer, ${ }^{d}$ Bogdan Faina, ${ }^{b}$ \\ Jiri Duchoslav, ${ }^{e}$ Matthias Kehrer, ${ }^{e}$ David Stifter, ${ }^{e}$ Heiko Groiss, ${ }^{\text {ef }}$ Verena Ney, ${ }^{b}$ \\ Andreas Ney ${ }^{b}$ and Philipp Stadler (D) *ac
}

\begin{abstract}
Currently, energy-efficient electrocatalytic oxygen evolution from water involves the use of noble metal oxides. Here, we show that highly $p$-conducting zinc cobaltite spinel $\mathrm{Zn}_{1.2} \mathrm{CO}_{1.8} \mathrm{O}_{3.5}$ offers an enhanced electrocatalytic activity for oxygen evolution. We refer to previous studies on sputtered $\mathrm{Zn}-\mathrm{Co}$ spinels with optimized conductivity for implementation as ( $p$-type) transparent conducting oxides. Based on that, we manufacture off-stoichiometric conducting $\mathrm{p}$-spinel catalytic anodes on tetragonal $\mathrm{Ti}, \mathrm{Au}-\mathrm{Ti}$ and hexagonal $\mathrm{Al}$-doped $\mathrm{ZnO}$ carriers and report the evolution of $\mathrm{O}_{2}$ at Tafel slopes between 40.5 and $48 \mathrm{mV} \mathrm{dec}^{-1}$ and at overpotentials between 0.35 and $0.43 \mathrm{~V}$ (at $10 \mathrm{~mA} \mathrm{~cm}{ }^{-2}$ ). The anodic stability, i.e., $50 \mathrm{~h}$ of continuous $\mathrm{O}_{2}$ electrolysis in $1 \mathrm{M} \mathrm{KOH}$, suggests that increasing the conductivity is advantageous for electrolysis, particularly for reducing the ohmic losses and ensuring activity across the entire surface. We conclude by pointing out the merits of improving $\mathrm{p}$-doping in $\mathrm{Zn}$-Co spinels by optimized growth on a tetragonal Ti-carrier and their application as dimension-stable $3 \mathrm{~d}$-metal anodes.
\end{abstract}

\section{Introduction}

Electrocatalytic water splitting is considered as a viable technology for hydrogen production. ${ }^{1-3}$ Alkaline water electrolyzers (AWEs) offer best-in-class energy efficiency to produce hydrogen and oxygen in large quantities. ${ }^{4}$ The crucial elements in AWEs are electrocatalytic 3d-metal (oxy)hydroxides and -oxides which are required to reduce the overpotentials of the oxygen evolution reaction (OER) to enable energy-efficient water splitting without the use of scarce and expensive elements. State-of-the-art alkalinemedium catalysts are dominated by $\mathrm{Ni}-\mathrm{Fe}\left(\right.$ oxy)hydroxides. ${ }^{5-7}$ These abundant catalyst systems achieve an acceptable compromise between overpotentials and anode stabilities; however, they

\footnotetext{
${ }^{a}$ Institute of Physical Chemistry, Johannes Kepler University Linz, Altenbergerstrasse 69, 4040 Linz, Austria. E-mail: philipp.stadler@jku.at

${ }^{b}$ Institute of Semiconductor and Solid State Physics, Johannes Kepler University Linz, Altenbergerstrasse 69, 4040 Linz, Austria

${ }^{c}$ Linz Institute of Technology, Johannes Kepler University Linz, Altenbergerstrasse 69, 4040 Linz, Austria

${ }^{d}$ Department of Physics and Astronomy, Uppsala University, Box 516, 751 20, Uppsala, Sweden

${ }^{e}$ Center for Surface and Nanoanalytics, Johannes Kepler University Linz, Altenbergerstrasse 69, 4040 Linz, Austria

${ }^{f}$ Christian Doppler Laboratory for Nanoscale Phase Transformations, Center for Surface and Nanoanalytics, Johannes Kepler University Linz, Altenberger Str. 69, 4040 Linz, Austria

$\dagger$ Electronic supplementary information (ESI) available: Material characterization and electrochemical characterization. See DOI: 10.1039/d1ma00157d
}

possess inherently poor electrical conductivities that impede the electron flow across a catalyst film and leads to Ohmic losses particularly at high current densities. ${ }^{8-10}$ Conductive additives, such as graphene oxide, carbon nanotubes and others, can help in increasing the conductivity and electrocatalytic performance; however, they come at the cost of anodic stabilities. ${ }^{11-13}$ Our strategy here is to increase the intrinsic electrical conductivity of the corresponding (electrocatalytic) oxide; hence, we select the zinc cobaltite spinel system (nominal $\mathrm{ZnCo}_{2} \mathrm{O}_{4}$ ) and seek adaptation in stoichiometry and growth to optimize electroconductivity and thus electrocatalytic OER performance. ${ }^{14-18}$ We demonstrate the manufacturing of dimension-stable anodes using a highly $\mathrm{p}$ doped $\mathrm{Zn}$-Co spinel on $\mathrm{Ti}$ (and native $\mathrm{TiO}_{2}$ ) and Al-doped $\mathrm{ZnO}$ conducting carriers. These catalytic systems exhibit a remarkable electrocatalytic performance. We adjust the spinel's $\mathrm{Zn}$ : Co ratio towards large p-doping, and increase the oxide conductivity and with that the effective geometric surface activity in the electrolysis; this represents an elementary advantage as compared to the insulating Ni-Fe (oxy)hydroxides; we add that p-doping has been reported to aid the kinetics in the inner Helmholtz plane in alkaline solutions. ${ }^{8,13,19} \mathrm{Zn}$-Co spinels can be intensively p-doped by defects, especially in epitaxic off-stoichometric films grown, e.g., on sapphire. Here, the deposition conditions are decisive to establish p-doped oxides achieving conductivities beyond $1 \mathrm{~S} \mathrm{~cm}^{-1} \cdot{ }^{20-22}$ Such conducting spinels are considered as alternative p-type transparent conducting oxides useful in various electronic devices. In this work, we study the adjusted off-stoichometric growth 
of a $\mathrm{Zn}$-Co spinel on titanium (plus native $\mathrm{TiO}_{2}$ ) and Al-doped $\mathrm{ZnO}$ as (tetragonal and hexagonal) carrier substrates. In addition, we refer to previous studies, where p-doped spinels were grown by reactive magnetron sputtering (RMS) from $\mathrm{ZnO} / \mathrm{Co}_{3} \mathrm{O}_{4}$ targets on sapphire (0001). This technique enables a precise control of the p-doping by matching the target composition ( $\mathrm{Zn}$ : Co) with the resulting $\mathrm{Zn}-\mathrm{Co}$ spinels at $\mathrm{Zn}$ : Co equal to $0.66(2: 3){ }^{23}$ This ratio is $30 \%$ of the nominal spinel $\left(\mathrm{ZnCo}_{2} \mathrm{O}_{4}, \mathrm{Zn}: \mathrm{Co}=0.5\right)$ and induces the desired offstoichiometry in the spinel with a hole carrier density typically beyond $1 \times 10^{21} \mathrm{~cm}^{-3}$. We reproduce this work on sapphire (0001) and report a hole density of $1.5 \times 10^{21} \mathrm{~cm}^{-3}$ and an electrical conductivity of $6.1 \mathrm{~S} \mathrm{~cm}^{-1}$ as measured by 4-probe resistivity and Hall measurements. Based on this, we employed these parameters on a titanium mesh (Ti-mesh with native $\mathrm{TiO}_{2}$ ) and Al-doped $\mathrm{ZnO}$ (Al:ZnO). For comparison, we grow control spinels on sapphire (0001) and rutile $\left(\mathrm{TiO}_{2}\right)$ to study the exact impact of the underlying substrate. We report that the Ti-mesh and Al:ZnO lead to spinels with different quality. While on tetragonal $\mathrm{TiO}_{2}$, the growth is similar to that of sapphire (0001) (and the control samples on rutile), and wurtzite (Al:ZnO) obviously induces larger polycrystallinity. This is also reflected in the OER electrolysis, where the spinel on the Ti-mesh shows a state-of-the-art electrocatalytic performance with a Tafel slope and an overpotential as low as $40.5 \mathrm{mV} \mathrm{dec}^{-1}$ and $0.35 \mathrm{~V}$ (at $10 \mathrm{~mA} \mathrm{~cm}^{-2}$ ), respectively, and a turn-over frequency (TOF) as high as $0.07 \mathrm{~s}^{-1}$, while on $\mathrm{Al}: \mathrm{ZnO}$, we observed a $0.08 \mathrm{~V}$ larger overpotential, but a similar Tafel slope; hence, we relate the minor activity to the poorer crystalline quality. We further studied the spinel on a 10-nm Au-covered Ti-mesh, in order to exclude the corrosion effects on the Ti mesh under large anodic bias. These anodes show a remarkable stability, but the Au-interlayer increases the spinel's overpotentials and Tafel slopes. In summary, our Zn-Co spinel/Ti-anodes are suitable for long-term continuous OER electrolysis and demonstrate that RMS-deposition is useful to obtain quasiepitaxic p-doped $\mathrm{Zn}$-Co spinels on titanium as dimension-stable electrocatalytic anodes. ${ }^{24-26}$ We report that the influence of the carrier substrate is decisive, particularly the tetragonal rutile systems impact the growth of the spinel oxide positively, while wurtzite, here exemplified with $\mathrm{Al}: \mathrm{ZnO}$, is less appropriate. This is further indicated by the performance of a few nanometer Au-covered Ti-mesh, where the overpotentials and Tafel slopes increased slightly. As such, this work shows that $\mathrm{Zn}$-Co spinels render stable electrocatalytic anodes when combined with titanium. These systems are suitable for electrolysis at high current densities without notable Ohmic losses. . $^{87,28}$

\section{Results and discussion}

$\mathrm{Zn}$-Co spinels are deposited by reactive magnetron sputtering (RMS) in the presence of an $\mathrm{Ar}-\mathrm{O}_{2}$ gas blend $\left(\mathrm{Ar}: \mathrm{O}_{2}=10: 0.5\right.$ sccm) at a pressure of $4 \times 10^{-3}$ mbar. The temperature and magnetron power are set to $623 \mathrm{~K}$ and $30 \mathrm{~W}$, respectively. We grow thin films at nominal $200 \mathrm{~nm}$ thickness. The exact thickness varies between 160 and $200 \mathrm{~nm}$ as measured by $\mathrm{X}$-ray reflectometry and profilometry. Zn-Co spinels are grown on the $c$-plane sapphire $\mathrm{Al}_{2} \mathrm{O}_{3}$ (0001) serving as reference substrates to perform bulk structural analysis by Rutherford backscattering (RBS) and bulk electrical transport by 4-probe resistivity/Hall measurements. For the electrocatalytic anodes, spinels are grown on a Ti-mesh with a native $\mathrm{TiO}_{2}$ including reference samples on $\mathrm{TiO}_{2}$ (rutile) to study the deposition on $\mathrm{TiO}_{2}$, and on Al-doped $\mathrm{ZnO}(\mathrm{Al}: \mathrm{ZnO})$ to study the deposition on sapphire to elucidate the electrocatalytic performance on different carrier substrates. The corresponding schematics of the Ti-mesh, electrochemical cell and related electrochemical reference measurements for $\mathrm{Al}: \mathrm{ZnO}$ and Ti-mesh are included in the $\mathrm{ESI} \dagger$ (Fig. S1-S4). The RMS preparation conditions, i.e., $\mathrm{Ar}$ : $\mathrm{O}_{2}=10: 0.5 \mathrm{sccm}$ flow ratio, $623 \mathrm{~K}$ at $30 \mathrm{~W}$ power, were employed to yield systematically $\mathrm{Zn}$-Co spinels with a stoichiometry composition of $\mathrm{Zn}_{1.2} \mathrm{Co}_{1.8} \mathrm{O}_{3.5}$, as measured by Rutherford backscattering spectrometry (RBS, Fig. 1a and b). We use a primary ion energy of $2 \mathrm{MeV} \mathrm{He}^{+}$and for comparison, we use $10 \mathrm{MeV} \mathrm{C}^{3+}$ to obtain the bulk composition. The resulting stoichiometry is derived from an itinerary fit. The $\mathrm{Zn}$ : Co ratio is thereby 0.65 , consistent with the target composition ( $\mathrm{ZnO}$ to $\mathrm{Co}_{3} \mathrm{O}_{4}$ at 2:3 during sputtering). The excess of $\mathrm{Zn}$ and the deficiency of $\mathrm{O}$ correspond to strong defect doping which is the characteristic of $\mathrm{Zn}$-Co spinels. ${ }^{22}$ The presence of large antisites, i.e., varying positions among $\mathrm{Zn}^{2+}: \mathrm{Co}^{2+}: \mathrm{Co}^{3+}$, has been reported earlier. ${ }^{22}$ Off-stoichiometries, as shown here, lead to strong p-doping. We denote that a similar composition of the surface is obtained using Auger-Meitner electron spectroscopy (AES, Fig. 4d).

In parallel, we study the electrical transport of the asdeposited $\mathrm{Zn}_{1.2} \mathrm{Co}_{1.8} \mathrm{O}_{3.5}$ by 4-probe resistivity and Hall measurements (Fig. 2a and b). The samples show a conductivity as high as $6.1 \mathrm{~S} \mathrm{~cm}^{-1}$ with a hole density of $1.5 \times 10^{21} \mathrm{~cm}^{-3}$ and mobility of $0.025 \mathrm{~cm}^{2} \mathrm{~V}^{-1} \mathrm{~s}^{-1}$ at $300 \mathrm{~K}$. The temperature coefficient of resistivity is negative and has an activation energy of $65 \mathrm{meV}$ (Fig. 2a, inset). A similar transport profile is reported in $\mathrm{Zn}$-Co spinels grown by pulsed laser deposition (PLD). ${ }^{31-33}$ In general, the mobility values of p-type PLD- and RMS-grown $\mathrm{Zn}$-Co spinels are comparatively low, which is related to the
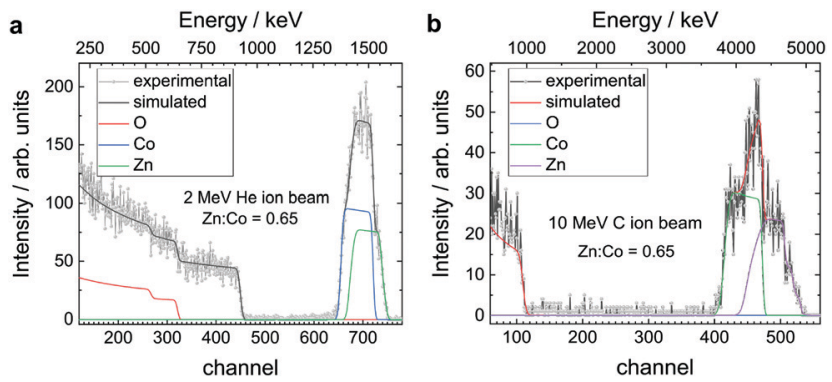

Fig. $1 \mathrm{Zn}_{1.2} \mathrm{CO}_{1.8} \mathrm{O}_{3.5}$ composition characterization. (a) Rutherford backscattering spectrometry (RBS, here: primary ion energy at $2 \mathrm{MeV} \mathrm{He}^{+}$) shows the (bulk) $\mathrm{Zn}$ : Co ratio of the as-deposited $\mathrm{Zn}$-Co spinel oxide at 0.65 . The analysis is conducted according to an itinerary fit. ${ }^{29,30}$ (b) The ratio of the composition metal constituents, as well as the homogeneity of their respective concentration, is additionally checked by RBS using $10 \mathrm{MeV} \mathrm{C}^{3+}$ ions. In summary, the bulk structure composition for the $\mathrm{Zn}-\mathrm{Co}$ spinel grown by RMS corresponds to the stoichiometry of $\mathrm{Zn}_{1.2} \mathrm{Co}_{1.8} \mathrm{O}_{3.5}$. 

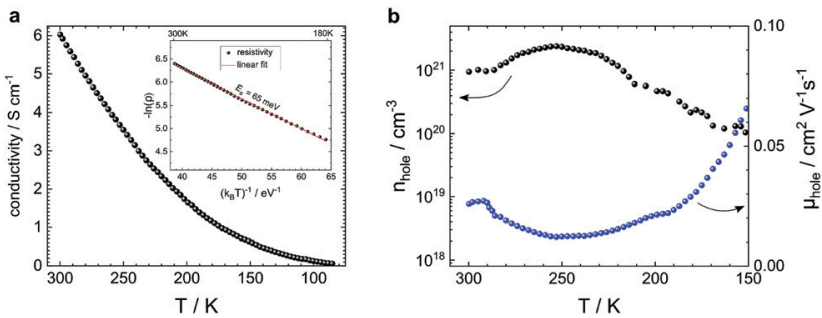

Fig. $2 \mathrm{Zn}_{1.2} \mathrm{CO}_{1.8} \mathrm{O}_{3.5}$ electrical transport characterization. (a) Bulk conductivity versus temperature of a 193-nm Zn-Co spinel on sapphire shows a negative temperature coefficient of resistivity with an activation energy of $65 \mathrm{meV}$ (inset). (b) Hall measurements (van der Pauw method) reveal a hole carrier density of above $10^{21} \mathrm{~cm}^{-3}$ and a mobility of $0.025 \mathrm{~cm}^{2} \mathrm{~V}^{-1} \mathrm{~s}^{-1}$.

strong presence of defects and the polycrystallinity of the sample. Here, the lattice mismatch between the spinel and the substrates (sapphire, $\mathrm{TiO}_{2}$, Al:ZnO, etc.) plays a major role. Table 1 summarizes the electrical parameters including a comparison with the discussed state-of-the-art performance. We denote that the RMS mobilities and conductivities of this work are superior to those of the PLD-grown spinels. Superior mobilities and conductivities are only obtained from spinelspinel lattice-matched epitaxic stacks $\left(\mathrm{MgAl}_{2} \mathrm{O}_{4} / \mathrm{Zn}-\mathrm{Co}\right.$ spinel). ${ }^{22}$

The low mobility and lattice mismatch implement tensions in the spinel structure emerging from the substrate. We present here the diffraction patterns of spinels grown on different potential carrier electrodes and the corresponding reference substrates: spinels on sapphire and sapphire/ $/ \mathrm{TiO}_{2}$ for reference; spinels on a Ti-mesh with native $\mathrm{TiO}_{2}$ and sapphire/Al:ZnO. All these substrates lead to an oxide with a characteristic fingerprint (222) diffraction pattern. However, these substrates induce a different peak intensity and width. The full width at half maximum (FWHM, insets Fig. 3a and b) allows the estimation of the average grain size using the Scherrer formula. The spinel/sapphire and spinel/ $/ \mathrm{TiO}_{2}$ show an equal or similar diffraction pattern and an average grain size of $\approx 30 \mathrm{~nm}$. This pattern is slightly broadened on the Ti-mesh $\left(\mathrm{FWHM}=0.28^{\circ}\right)$ and yields a relative average grain size of $28.6 \mathrm{~nm}$. A substantial shift/broadening is observed on the spinel/Al:ZnO (approx. FWHM at $0.39^{\circ}$ corresponding to the $21 \mathrm{~nm}$ average grain size and the smallest relative (222) spinel intensity). We conclude that while Al:ZnO (wurtzite) has a detrimental impact on the spinel, the sapphire, $\mathrm{TiO}_{2}$ and Ti-mesh (with native oxide) lead to practically equal growth (Table 2 and ESI, $\uparrow$ Table S1, Fig. S7). To study the OER, we manufacture electrocatalytic anodes using $\mathrm{Zn}_{1.2} \mathrm{Co}_{1.8} \mathrm{O}_{3.5}$ deposited on the Ti-mesh and Al:ZnO in $1 \mathrm{M} \mathrm{KOH}(\mathrm{pH}=13.96)$ as the electrolyte. We perform cyclic voltammetry and chronoamperometry to explore

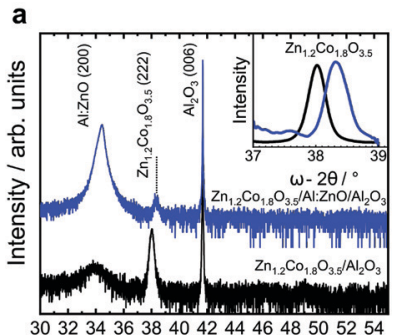

$\omega-2 \theta /^{\circ}$

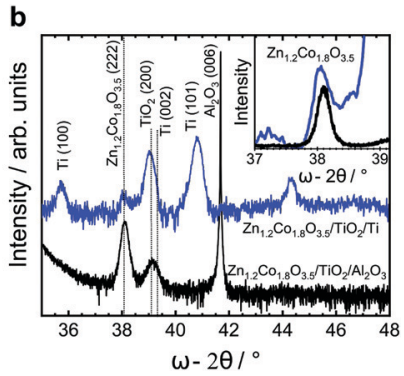

Fig. $3 \mathrm{X}$-ray diffraction pattern of $\mathrm{Zn}_{1.2} \mathrm{CO}_{1.8} \mathrm{O}_{3.5}$. Diffraction pattern of $\mathrm{Zn}-\mathrm{Co}$ spinel on (a) sapphire and Al:ZnO/sapphire. The spinel (222) reflection at $38^{\circ}(2 \Theta)$ shifts by $+0.3^{\circ}$ on $\mathrm{Al}: \mathrm{ZnO}$ (normalized zoom in the inset). The peak broadened on Al: $\mathrm{ZnO}$ indicating larger tensions/defects from the lattice mismatch wurtzite/spinel as compared to sapphire/spinel. (b) Growth of $\mathrm{Zn}-\mathrm{Co}$ spinels on rutile $\mathrm{TiO}_{2}$ /sapphire and on a Ti-mesh with native $\mathrm{TiO}_{2}$. Both peaks are comparable to the sapphire reference. On $\mathrm{Al}: \mathrm{ZnO}$, the large lattice mismatch wurtzite/spinel leads to a broader and less intense diffraction pattern.

the $\mathrm{O}_{2}$ evolution and the relative stability over time using the electrochemical half-cell (anode space separated with a glass frit, ESI, $\dagger$ Fig. S13). As the reference electrode we deploy an electrolytematched $\mathrm{Hg}|\mathrm{HgO}| 1 \mathrm{M} \mathrm{KOH} \|$ system calibrated at $+0.098 \mathrm{~V} v$ s. SHE. As the counter electrode (in the cathode space) we use Ni. The spinel-covered Ti-meshes and the $\mathrm{Al}: \mathrm{ZnO} / \mathrm{sapphire}$ substrates are mounted in the anode space. Linear sweep voltammetry and chronoamperometry are performed under stirring or flow (for the Al:ZnO system, a corresponding cell is designed to bury the $\mathrm{KOH}$-sensitive Al:ZnO completely underneath the active spinel). In addition, we conduct reference cyclic voltammetry and chronoamperometry on a plane Ti-mesh without spinels. The active area of the Ti-mesh is calculated according to the surface-volume factor of the mesh (a factor of 0.75 compared to the projected plate area, ESI, $\dagger$ Fig. S2). This value is confirmed by probing the dimension using scanning electron microscopy. The active area of the spinel/ $\mathrm{Al}: \mathrm{ZnO}$ is directly measured (a ring with a radius of $2.5 \mathrm{~mm}$ ). The cyclic voltammetry is swept at a constant ratio with a repeating factor of 50 cycles between 10 and $50 \mathrm{mV} \mathrm{s}^{-1}$. The scans show the increase of the electrocatalytic current to $10 \mathrm{~mA} \mathrm{~cm}$ cm $^{-2}$ at an overpotential as low as $0.35 \mathrm{~V}$ and a Tafel slope as low as $40.5 \mathrm{mV} \mathrm{dec}{ }^{-1}$ (CVs, Fig. 4a and Tafel analysis, Fig. 4c). The activity of the (nominally) 200-nm thin film remains stable after several hours of continuous evolution of $\mathrm{O}_{2}$ (Fig. 4b). Similar results at slightly higher overpotentials are observed for the $\mathrm{Al}: \mathrm{ZnO} /$ sapphire using a flow cell. Here, the overpotential at $10 \mathrm{~mA} \mathrm{~cm}{ }^{-2}$ reaches $0.43 \mathrm{~V}$ with a Tafel slope at $42.2 \mathrm{mV} \mathrm{dec}^{-1}$ (summary in Table 3). We denote that the spinel/Al:ZnO electrode shows a gradual

Table 1 Electrical parameters of polycrystalline p-type Co-spinels

\begin{tabular}{|c|c|c|c|c|c|}
\hline System & Method & $\sigma / \mathrm{S} \mathrm{cm}^{-1}$ & $n_{\text {hole }} / \mathrm{cm}^{-3}$ & $\mu_{\mathrm{H}} / \mathrm{cm}^{2} \mathrm{~V}^{-1} \mathrm{~s}^{-1}$ & Ref. \\
\hline $\mathrm{Zn}_{x} \mathrm{Co}_{3-x} \mathrm{O}_{4}$ & PLD & 5 & $0.5-2 \times 10^{21}$ & $0.01-0.06$ & Schein et $a l^{34}$ \\
\hline
\end{tabular}

${ }^{a}$ Epitaxic $\mathrm{ZnCo}_{2} \mathrm{O}_{4}-\mathrm{MgAl}_{2} \mathrm{O}_{4}$ PLD stacks. 
Table 2 Structural parameters of polycrystalline $p$-doped $Z n$-Co spinels

\begin{tabular}{lllll}
\hline & & $\begin{array}{l}\text { Peak spinel } \\
\text { Substrate }\end{array}$ & Crystal family & FWH/ \\
& $(22) / 2 \theta(\mathrm{deg})$ & $2 \theta(\mathrm{deg})$ & $\tau^{a} / \mathrm{nm}$ \\
\hline Sapphire (0001) & Hexagonal & 38.0 & 0.25 & 31.8 \\
Rutile & Tetragonal & 38.092 & 0.25 & 32 \\
Ti-Mesh (native $\left.\mathrm{TiO}_{2}\right)$ & Tetragonal & 38.092 & 0.28 & 28.6 \\
Al:ZnO (wurtzite) & Hexagonal & 38.3 & 0.39 & 21
\end{tabular}

${ }^{a}$ Scherrer analysis with $\lambda=0.15406 \mathrm{~nm}\left(\mathrm{Cu} \mathrm{K}_{\alpha 1}\right)$ and shape factor $K=0.89$ (spherical).

a

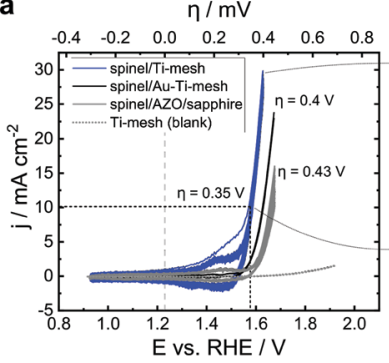

C
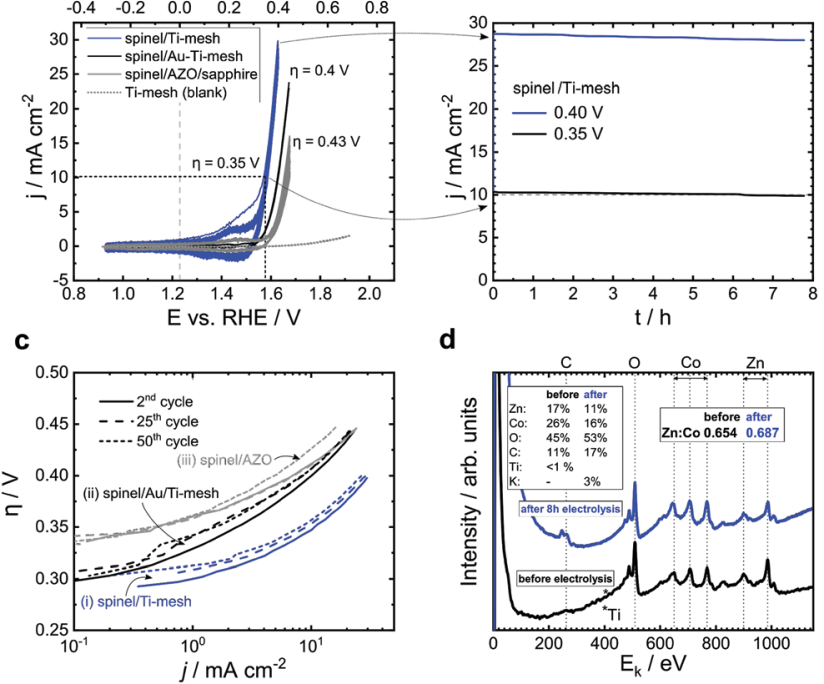

d

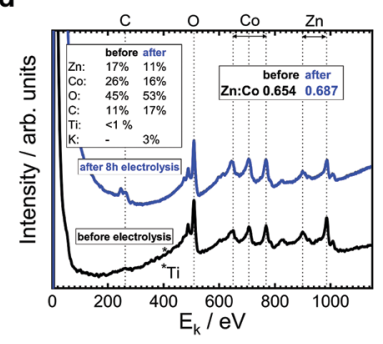

Fig. 4 Electrocatalytic performance and stability analysis of p-doped conducting spinel $\mathrm{Zn}_{1.2} \mathrm{CO}_{1.8} \mathrm{O}_{3.5}$ on (i) Ti-mesh, (ii) Au-covered Ti-Mesh and (iii) Al-doped $\mathrm{ZnO}(\mathrm{AL}: \mathrm{ZnO}$ ). (a) Cyclic voltammograms with 50 repeats at $50 \mathrm{mV} \mathrm{s}^{-1}$ in $1 \mathrm{M} \mathrm{KOH}$ (reference electrode $\mathrm{Hg} \mid \mathrm{HgOl} 1 \mathrm{M} \mathrm{KOH} \|$ at $+0.098 \mathrm{~V}$ vs. SHE) and (b) chronoamperometric ( $\left.j_{\text {anodic }}\right)$ scans of the superior spinel/Ti-mesh for $8 \mathrm{~h}$ at 0.35 and $0.4 \mathrm{~V}$ overpotentials. (c) Electrocatalytic Tafel performance including change by time (dashed lines show the 25th and 50th cycles). The Tafel slopes correspond to 40.5 (spinel/Ti-mesh), 48.5 (spinel/Au/Ti-mesh) and $42.2 \mathrm{mV} \mathrm{dec}{ }^{-1}$ (spinel/Al:ZnO), respectively. The slopes are extracted from the linear regime between 0.1 and $1 \mathrm{~mA} \mathrm{~cm}{ }^{-2}, \mathrm{ESI}, \dagger$ Fig. S13. (d) Auger-Meitner electron spectroscopy (AES) before and after $8 \mathrm{~h}$ of OER electrolysis on spinel/Ti-mesh. The composition after electrolysis indicates a relative increase of $\mathrm{Zn}$, i.e., the $\mathrm{Zn}-\mathrm{Co}$ spinel loses a minor amount of Co-moieties during electrolysis. The surface composition before electrolysis is in agreement with the RBS from Fig. 1.

decomposition in $1 \mathrm{M} \mathrm{KOH}$. The parallel conducted chronoamperometric scans of the Ti-mesh show that the present configuration allows testing over several hours under stable currents. We confirm the stability of the electrocatalyst by crosschecking the Auger-Meitner photoelectron pattern (AES, recorded ex situ before and after electrolysis, Fig. 4d). The $\mathrm{Zn}$ content decreases on the surface, i.e., the $\mathrm{Zn}$ : Co decreases from 0.65 to 0.62 . We denote that the surface is contaminated with the residual electrolyte (K-peak and increasing carbonate from exposure to ambient air). In longterm measurements, we also take the anodic corrosion of the Ti-mesh into account. Since we observe the growth of $\mathrm{TiO}_{2}$ after multiple scans (ESI, $\dagger$ Fig. S12), we sandwich a thin Au-layer

Table $3 \mathrm{Zn}_{1.2} \mathrm{CO}_{1.8} \mathrm{O}_{3.5}$ performance in $1 \mathrm{M} \mathrm{KOH}$ : Tafel slope and overpotentials $(\eta)$ at $298 \mathrm{~K}$ on different substrates as compared to NiFe hydroxides under similar conditions

\begin{tabular}{|c|c|c|c|c|c|}
\hline Anode stack & $\begin{array}{l}\text { Tafel slope/ } \\
\text { mV dec }^{-1}\end{array}$ & $\eta / \mathrm{V}$ & $\begin{array}{l}\operatorname{Load}^{b} / \\
\mu \mathrm{g} \mathrm{cm}^{-2}\end{array}$ & $\mathrm{TOF}^{a} / \mathrm{s}^{-1}$ & Ref. \\
\hline Spinel/Ti-mesh & 40.5 & 0.35 & 90 & 0.07 & This work \\
\hline Spinel/Au-Ti-mesh & 48.5 & 0.4 & 90 & 0.02 & This work \\
\hline Spinel/Al:ZnO & 42.2 & 0.43 & 180 & $<0.01$ & This work \\
\hline $\mathrm{NiFe}-\mathrm{LDH}^{c} / \mathrm{GC}^{d}$ & 67 & 0.347 & 70 & 0.01 & 10 \\
\hline 3D-NiFe-LDH/Ni & 50 & 0.250 & 1000 & 0.028 & 9 \\
\hline $\mathrm{Ni}-\mathrm{Fe} / \mathrm{Au}$ & 58 & 0.331 & 140 & - & 36 \\
\hline
\end{tabular}

${ }^{a}$ At $\eta=0.35 \mathrm{~V} .{ }^{b}$ Electrocatalyst load mass. ${ }^{c}$ Layered double hydroxide. ${ }^{d}$ Glassy carbon.

between the spinel and the Ti-mesh. The interlayer leads to an increased overpotential of $0.4 \mathrm{~V}$ (i.e. $+0.05 \mathrm{~V}$ ) beyond the plane Timesh (Fig. 4a and ESI, $\dagger$ Fig. S11), but allows us to perform $50 \mathrm{~h}$ of continuous $\mathrm{O}_{2}$ electrolysis with suppressed $\mathrm{Ti}^{-} \mathrm{TiO}_{2}$ corrosion. Here, the Faraday currents gradually decrease by $5 \%$ compared to the initial value which proves the stability of the $\mathrm{Zn}-\mathrm{Co}$ spinel (CV and chronoamperometry of Ti/Au in the ESI, $\dagger$ Fig. S11). In general, the Au-covered Ti-mesh shows results similar to the Ti-mesh (Tafel slopes are almost equal). The electrocatalytic performance on $\mathrm{Al}: \mathrm{ZnO}$ is lower as compared to that on the Ti-mesh. We refer here to the XRD study and the poorer signal quality of the spinel on $\mathrm{Al}: \mathrm{ZnO}$ indicating a larger polycrystallinity. In combination, these results show that the native $\mathrm{TiO}_{2}$ on the Ti-mesh allows the growth of epitaxic $\mathrm{Zn}_{1.2} \mathrm{Co}_{1.8} \mathrm{O}_{3.5}$ on sapphire or rutile, while the lattice mismatch limits the application of spinel/Al:ZnO. In combination, spinel on titanium (and $\mathrm{TiO}_{2}$ ) is attractive for electrocatalytic anodes. Particularly by optimized growth, shown here using sputtering, p-doped spinels unfold a state-of-the-art electrocatalytic performance, and in view of their intrinsic conductivity, they can serve as attractive electrocatalytic oxides for large-scale OER electrocatalysis performed at high current densities.

\section{Conclusions}

In summary, we show that the reactive magnetron sputtering from $\mathrm{ZnO} / \mathrm{Co}_{3} \mathrm{O}_{4}(2: 3)$ targets leads to the growth of p-type conducting $\mathrm{Zn}$-Co spinels with the composition of $\mathrm{Zn}_{1.2} \mathrm{Co}_{1.8}$ $\mathrm{O}_{3.5}$. This oxide is deposited on a Ti-mesh (with native $\mathrm{TiO}_{2}$ ) and $\mathrm{Al}: \mathrm{ZnO}$, and for comparison, on sapphire and $\mathrm{TiO}_{2}$ (rutile), to elucidate the impact of the substrate. We find that the growth on $\mathrm{TiO}_{2}$ is similar to that on sapphire. This can be used to manufacture electrocatalytic anodes based on Ti-meshes with native $\mathrm{TiO}_{2}$ and spinels that exhibit a state-ofthe-art electrocatalytic OER performance as compared to that of common alkaline electrocatalyst systems. Furthermore, we manufacture anodes from spinels grown on Al-doped $\mathrm{ZnO}$ and show that the poorer structural quality leads to lower electrocatalytic performance. We conclude by pointing out the merit of reactive magnetron sputtering to obtain zinc-rich, p-conducting spinels for the OER directly deposited on a Ti-mesh at moderate temperatures. We find that the growth on the Ti-mesh with its (rutile) $\mathrm{TiO}_{2}$ layer is beneficial for 
columnar spinel growth to ultimately demonstrate dimensionstable anodes for the OER. In this sense, the work here is inspired by the high conductivities of the corresponding $\mathrm{Zn}$-based ternary spinels $\mathrm{ZnRu}_{2} \mathrm{O}_{4}$ and $\mathrm{ZnIr}_{2} \mathrm{O}_{4},{ }^{31,37-40}$ i.e., to seek improvement in the electrical conductivity for $3 \mathrm{~d}$-metal oxides as one path to improve the OER on titanium carriers.

\section{Experimental section}

\subsection{RMS growth of spinel-type $\mathrm{Zn}_{1.2} \mathrm{Co}_{1.8} \mathrm{O}_{3.5}$}

The spinel-type $\mathrm{Zn}_{1.2} \mathrm{Co}_{1.8} \mathrm{O}_{3.5}$ was grown in an ultra-high vacuum (UHV) chamber (base pressure $\sim 2 \times 10^{-9} \mathrm{mbar}$ ) by reactive magnetron sputtering (RMS) from a $\mathrm{ZnO} / \mathrm{Co}_{3} \mathrm{O}_{4}(2: 3)$ target onto a heated substrate (heating temperature $T_{\mathrm{H}}=623 \mathrm{~K}$ ) with an argon-to-oxygen ratio (purity: $6 \mathrm{~N}$ ) of $\mathrm{Ar}: \mathrm{O}_{2}=10: 0.5$ standard cubic centimeter per minute at a working/deposition pressure of $4 \times 10^{-3}$ mbar with a magnetron power of $30 \mathrm{~W}$. Under these conditions, the sputter rate usually is around $3.5 \mathrm{~nm} \mathrm{~min}{ }^{-1} .{ }^{23}$ The thickness of the deposited $\mathrm{Zn}_{1.2} \mathrm{Co}_{1.8} \mathrm{O}_{3.5}$ was measured by X-ray reflectivity (Fig. S10, ESI $\dagger$ ).

Hall measurements. The electrical measurements of $\mathrm{Zn}_{1.2} \mathrm{Co}_{1.8} \mathrm{O}_{3.5}$ (on c-sapphire, $\mathrm{Al}_{2} \mathrm{O}_{3}$ (0001), CrysTec $\mathrm{GmbH}$ ) were performed in a van der Pauw configuration between $70 \mathrm{~K}$ and $300 \mathrm{~K} .193 \mathrm{~nm}$ films on $1 \times 1 \mathrm{~cm}^{2}$ sapphire were contacted using indium/gold leads. The measurements were carried out at pressures in the $10^{-5}$ mbar range. The sample holder was connected to a refrigerator-cooled cryostat (LeyboldHeraeus RNK 10-300 and LakeShore Cryotronics 8400 Series HMS). The Hall constant and resistivity were measured under a maximum magnetic field of $0.91 \mathrm{~T}$ (AC and DC mode) and a current of $1 \mathrm{~mA}$. Details of the Hall parameters are presented in the ESI $\dagger$ (Fig. S18-S21).

Ion beam analysis. The composition of the $\mathrm{Zn}-\mathrm{Co}$ spinel oxide was determined accurately by ion beam analysis. For this, we deployed Rutherford backscattering spectrometry (RBS) using $2 \mathrm{MeV} \mathrm{He}^{+}$as well as $10 \mathrm{MeV}{ }^{12} \mathrm{C}^{3+}$ primary beams at the Tandem Laboratory at Uppsala University. To disentangle the element-specific contributions, the spectra were analyzed using SIMNRA software. ${ }^{29}$ Details of the experimental setup are described elsewhere. ${ }^{30}$ The complementary comparison of the $2 \mathrm{MeV} \mathrm{He}{ }^{+}$and $10 \mathrm{MeV}^{12} \mathrm{C}^{3+}$ primary beams led to the bulk stoichiometric composition of $\mathrm{Zn}: \mathrm{Co}: \mathrm{O}$ in summary, which is $\mathrm{Zn}_{1.2} \mathrm{Co}_{1.8} \mathrm{O}_{3.5}$. We show that the penetration depth of the ion beams exceeds the thickness of the film $(150 \mathrm{~nm})$.

Auger-Meitner electron spectroscopy. The Auger-Meitner electron spectroscopy (AES) measurements were performed using a scanning AES microscope JAMP-9500 F (JEOL, JP) equipped with a hemispherical electron energy analyzer and a channeltron detector. The AES spectra were recorded with an acceleration voltage of $10 \mathrm{kV}$ and an electron beam current of $20 \mathrm{nA}$, which resulted in a diameter of approximately $30 \mathrm{~nm}$ for the measurement spot.

X-ray diffraction and TEM. In order to probe the crystal properties of the grown films, XRD was performed with an X'Pert PRO PANalytical MRD diffractometer. The X-ray source consists of a copper anode $\left(K_{\alpha 1}, \lambda=0.15406 \mathrm{~nm}\right)$ with hybrid two-crystal Germanium (220) Bartels type beam optics. The diffractograms were recorded with a voltage of $40 \mathrm{kV}$ and an anode current of $40 \mathrm{~mA}$. The reference and extended diffractograms are presented in the ESI $\dagger$ (Fig. S5-S7).

The structure of the $\mathrm{Zn}_{1.2} \mathrm{Co}_{1.8} \mathrm{O}_{3.5} / \mathrm{Ti}$-mesh was investigated using (scanning) transmission electron microscopy (TEM). An overview of the layer system (Fig. S8 and S9) shows the Ti-mesh covered by layered $\mathrm{TiO}_{2}$ with varying thickness (20 to $100 \mathrm{~nm}$ ) and on top of $\mathrm{Zn}_{1.2} \mathrm{Co}_{1.8} \mathrm{O}_{3.5}$ with a homogeneous thickness of $\approx 150 \mathrm{~nm}$. For the TEM sample preparation, the active layer was covered with Pt deposition to protect it during FIB (focused ionbeam) cutting. The $\mathrm{Zn}_{1.2} \mathrm{Co}_{1.8} \mathrm{O}_{3.5}$ consists of thin columnar grains with different diameters in the range of 10-40 nm (Fig. 3c). A rough statistic from 20 measured grains leads to an average domain size $(\tau)$ of $24 \mathrm{~nm}$ (in agreement with the Scherrer analysis, Fig. S5-S7 and Table 2). Most of the columns reach from the $\mathrm{TiO}_{2}$ to the top of the layer. The crystallinity of these columnar $\mathrm{Zn}_{1.2} \mathrm{Co}_{1.8} \mathrm{O}_{3.5}$ grains was additionally proven by phase contrast imaging performed by conventional TEM (ESI, $\dagger$ Fig. S8 and S9). Focused ion beam (FIB) cutting with a CrossBeam 1540 XB (ZEISS, Germany) was used to prepare the thin cross-sectional lamella for the TEM investigation. Several layers of electron and ion beam Pt deposition have been used for surface protection. The FIB was operated at $30 \mathrm{kV}$ for sample cutting and lift-out. To achieve a high lamella quality and to reduce the amorphization of the sample, a Ga acceleration voltage of $5 \mathrm{kV}$ was used for final thinning. The scanning and conventional transmission electron microscopy (TEM) investigation was performed using a JEM-2200FS (JEOL, Japan operated at an acceleration voltage of $200 \mathrm{kV}$ ).

Electrochemical measurements. For the evaluation of the electrocatalytic performance, a conventional $\mathrm{H}$-cell with a threeelectrode configuration was used. $\mathrm{Zn}_{1.2} \mathrm{Co}_{1.8} \mathrm{O}_{3.5}$ on a titanium mesh (Goodfellow, $5 \mathrm{~N}-\mathrm{Ti}$, size $1 \times 1 \mathrm{~cm}^{2}$, aspect ratio $0.75: 1$, effective area $0.75 \mathrm{~cm}^{2}$, SEM picture in the ESI, $\uparrow$ Fig. S2 and S16) carrier electrode served as the working electrode (WE), whereas the counter electrode (CE) consisted of a (much larger) nickel plate. The highly alkaline $1 \mathrm{M} \mathrm{KOH}$ (purity: $85 \%$, Alfa Aesar) electrolyte requires the use of an (electrolyte-matched) $\mathrm{Hg}|\mathrm{HgO}| 1 \mathrm{M} \mathrm{KOH} \|$ reference electrode (RE). A HANNA Instruments $\mathrm{pH} 211$ microprocessor $\mathrm{pH}$-meter was used to measure the $\mathrm{pH}$ values of the electrolyte. The solution in the $\mathrm{WE}$ compartment was stirred with a magnetic stirrer $(\sim 350 \mathrm{rpm})$. In this cell configuration, oxygen evolution took place in the WE and hydrogen evolution in the CE compartment, which are separated using a glass frit (Fig. S17, ESI $\dagger$ ). The RE was placed close to the WE. Its standard electrode potential is $E_{\mathrm{Hg} \mid \mathrm{HgO}}^{0}=+0.098 \mathrm{~V}$ versus the standard hydrogen electrode (vs. SHE). Therefore, the measured potential versus the reversible hydrogen electrode (RHE) is:

$$
E_{\mathrm{RHE}}=E_{\mathrm{Hg} \mid \mathrm{HgO}}+0.098 \mathrm{~V}+0.0591 V \cdot p H .
$$

The electrochemical measurements were performed with a JAISSLE potentiostat/galvanostat IMP 88 PC. Electrochemical 
impedance spectroscopy was used to determine the cell parameters by applying an AC voltage with an amplitude of $50 \mathrm{mV}$ in the range from $0.1 \mathrm{~Hz}$ to $100 \mathrm{kHz}$. The measurement allowed the determination of the electrolyte, sample and membrane resistances $\left(R_{\mathrm{e}}, R_{\mathrm{S}}\right.$ and $R_{\mathrm{m}}$, respectively) (ESI, $\dagger$ Table $\mathrm{S} 2$ and Fig. S14) as well as the electrochemical surface area with $j v s$. scan rate (Fig. S16, ESI $\dagger$ ). The recorded currents during cyclic voltammetry were normalized to the electrochemical surface area. The geometric surface area was determined from the SEM measurements which yielded a ratio of $0.75\left(0.75 \mathrm{~cm}^{2}\right.$ active area per $1 \mathrm{~cm}^{2}$ mesh) including purity crosscheck and elemental analysis after electrolysis by X-ray/Auger-Meitner photoelectron spectroscopy (Fig. S2, S4d and S19, ESI $\dagger$ ). All voltammograms (cyclic, Tafel slope) were derived from the scans conducted at $10 \mathrm{mV} \mathrm{s}^{-1}$. The headspace gas was analyzed by gas-chromatography (presence of $\mathrm{O}_{2}$, Fig. S24, ESI $\dagger$ ) to calculate the Faraday yield for hydrogen and oxygen. We found quantitative yields close to $98 \%$. The statistical evaluation of the different experiments on the electrocatalytic activity of $\mathrm{Zn}_{1.2} \mathrm{Co}_{1.8} \mathrm{O}_{3.5}$ and high current density $\left(>500 \mathrm{~mA} \mathrm{~cm}{ }^{-2}\right)$ data are included in the ESI $\dagger$ (Table S3 and Fig. S18, S15).

\section{Conflicts of interest}

There are no conflicts to declare.

\section{Acknowledgements}

The authors acknowledge the financial support from the Austrian Science Foundation (FWF I3822-N37, Sustainable Catalysis and P26164-N20), the Linz Institute of Technology (LIT, LIT-2017-4-YOU-005, biopolymer-based carbonate reduction) at the Johannes Kepler University Linz, the European Regional Development Fund (EFRE, IWB2014-2020, 2018-98299 Artificial Food and project BIOCARB-K), and the Government of Upper Austria. The authors gratefully acknowledge VR-RFI (Contract No. 2017-00646 9) and the Swedish Foundation for Strategic Research (SSF, Contract No. RIF14-0053) for supporting accelerator operation at Uppsala University (Sweden). The financial support from the Austrian Federal Ministry for Digital and Economic Affairs, the National Foundation for Research, Technology and Development, and the Christian Doppler Research Association is gratefully acknowledged. The authors thank Günter Hesser for TEM sample preparation and fruitful discussions.

\section{Notes and references}

1 N.-T. Suen, S.-F. Hung, Q. Quan, N. Zhang, Y.-J. Xu and H. M. Chen, Chem. Soc. Rev., 2017, 46, 337-365.

2 I. C. Man, H. Su, F. Calle-Vallejo, H. A. Hansen, J. I. Martínez, N. G. Inoglu, J. Kitchin, T. F. Jaramillo, J. K. Nørskov and J. Rossmeisl, ChemCatChem, 2011, 3, 1159-1165.
3 I. Katsounaros, S. Cherevko, A. R. Zeradjanin and K. J. J. Mayrhofer, Angew. Chem., Int. Ed., 2014, 53, 102-121.

4 C. C. L. McCrory, S. Jung, J. C. Peters and T. F. Jaramillo, J. Am. Chem. Soc., 2013, 135, 16977-16987.

5 J. Mohammed-Ibrahim, J. Power Sources, 2020, 448, 227375. 6 J. Mohammed-Ibrahim, J. Power Sources, 2020, 448, 227375.

7 R. Chen, S. Hung, D. Zhou, J. Gao, C. Yang, H. Tao, H. B. Yang, L. Zhang, L. Zhang, Q. Xiong, H. M. Chen and B. Liu, Adv. Mater., 2019, 31, 1903909.

8 Y. Matsumoto and E. Sato, Mater. Chem. Phys., 1986, 14, 397-426.

9 L. Yu, H. Zhou, J. Sun, I. K. Mishra, D. Luo, F. Yu, Y. Yu, S. Chen and Z. Ren, J. Mater. Chem. A, 2018, 6, 13619-13623.

10 C. Peng, N. Ran, G. Wan, W. Zhao, Z. Kuang, Z. Lu, C. Sun, J. Liu, L. Wang and H. Chen, ChemSusChem, 2020, 13, 811-818.

11 X. Long, J. Li, S. Xiao, K. Yan, Z. Wang, H. Chen and S. Yang, Angew. Chem., 2014, 126, 7714-7718.

12 M. Gong, Y. Li, H. Wang, Y. Liang, J. Z. Wu, J. Zhou, J. Wang, T. Regier, F. Wei and H. Dai, J. Am. Chem. Soc., 2013, 135, 8452-8455.

13 D. M. Morales, S. Barwe, E. Vasile, C. Andronescu and W. Schuhmann, ChemPhysChem, 2019, 20, 3030-3036.

14 N. Manca, D. J. Groenendijk, I. Pallecchi, C. Autieri, L. M. K. Tang, F. Telesio, G. Mattoni, A. McCollam, S. Picozzi and A. D. Caviglia, Phys. Rev. B, 2018, 97, 081105.

15 E. Fabbri, A. Habereder, K. Waltar, R. Kötz and T. J. Schmidt, Catal. Sci. Technol., 2014, 4, 3800-3821.

16 T. W. Kim, M. A. Woo, M. Regis and K.-S. Choi, J. Phys. Chem. Lett., 2014, 5, 2370-2374.

17 S. Han, S. Liu, R. Wang, X. Liu, L. Bai and Z. He, ACS Appl. Mater. Interfaces, 2017, 9, 17186-17194.

18 X. Liu, Z. Chang, L. Luo, T. Xu, X. Lei, J. Liu and X. Sun, Chem. Mater., 2014, 26, 1889-1895.

19 P. W. Menezes, A. Indra, A. Bergmann, P. Chernev, C. Walter, H. Dau, P. Strasser and M. Driess, J. Mater. Chem. A, 2016, 4, 10014-10022.

20 M. Stoica and C. S. Lo, New J. Phys., 2014, 16, 055011.

21 Y. Shi, P. F. Ndione, L. Y. Lim, D. Sokaras, T.-C. Weng, A. R. Nagaraja, A. G. Karydas, J. D. Perkins, T. O. Mason, D. S. Ginley, A. Zunger and M. F. Toney, Chem. Mater., 2014, 26, 1867-1873.

22 X. C. Huang, J. Y. Zhang, M. Wu, S. Zhang, H. Y. Xiao, W. Q. Han, T.-L. Lee, A. Tadich, D.-C. Qi, L. Qiao, L. Chen and K. H. L. Zhang, Phys. Rev. B, 2019, 100, 115301.

23 B. Henne, V. Ney, K. Ollefs, F. Wilhelm, A. Rogalev and A. Ney, Sci. Rep., 2015, 5, 16863.

24 T. Reier, I. Weidinger, P. Hildebrandt, R. Kraehnert and P. Strasser, ECS Trans., 2013, 58, 39-51.

25 T. Reier, D. Teschner, T. Lunkenbein, A. Bergmann, S. Selve, R. Kraehnert, R. Schlögl and P. Strasser, J. Electrochem. Soc., 2014, 161, F876-F882.

26 B. Johnson, F. Girgsdies, G. Weinberg, D. Rosenthal, A. Knop-Gericke, R. Schlögl, T. Reier and P. Strasser, J. Phys. Chem. C, 2013, 117, 25443-25450.

27 C. Iwakura, M. Nishioka and H. Tamura, Nippon Kagaku Kaishi, 1982, 1136-1140. 
28 J. A. Koza, Z. He, A. S. Miller and J. A. Switzer, Chem. Mater., 2012, 24, 3567-3573.

29 M. Mayer, SIMNRA User's Guide, 2017, https://home.mpcdf. mpg.de/mam/SIMNRA-Users-Guide.pdf.

30 M. Moro, R. Holeňák, L. Zendejas Medina, U. Jansson and D. Primetzhofer, Thin Solid Films, 2019, 686, 137416.

31 M. N. Amini, H. Dixit, R. Saniz, D. Lamoen and B. Partoens, Phys. Chem. Chem. Phys., 2014, 16, 2588.

32 J. D. Perkins, T. R. Paudel, A. Zakutayev, P. F. Ndione, P. A. Parilla, D. L. Young, S. Lany, D. S. Ginley, A. Zunger, N. H. Perry, Y. Tang, M. Grayson, T. O. Mason, J. S. Bettinger, Y. Shi and M. F. Toney, Phys. Rev. B: Condens. Matter Mater. Phys., 2011, 84, 205207.

33 H. J. Kim, I. C. Song, J. H. Sim, H. Kim, D. Kim, Y. E. Ihm and W. K. Choo, J. Appl. Phys., 2004, 95, 7387-7389.
34 F.-L. Schein, M. Winter, T. Böntgen, H. von Wenckstern and M. Grundmann, Appl. Phys. Lett., 2014, 104, 022104.

35 C.-S. Cheng, M. Serizawa, H. Sakata and T. Hirayama, Mater. Chem. Phys., 1998, 53, 225-230.

36 X. Yu, M. Zhang, W. Yuan and G. Shi, J. Mater. Chem. A, 2015, 3, 6921-6928.

37 L. C. Seitz, C. F. Dickens, K. Nishio, Y. Hikita, J. Montoya, A. Doyle, C. Kirk, A. Vojvodic, H. Y. Hwang, J. K. Norskov and T. F. Jaramillo, Science, 2016, 353, 1011-1014.

38 J. A. Gauthier, C. F. Dickens, L. D. Chen, A. D. Doyle and J. K. Nørskov, J. Phys. Chem. C, 2017, 121, 11455-11463.

39 Y. Lee, J. Suntivich, K. J. May, E. E. Perry and Y. Shao-Horn, J. Phys. Chem. Lett., 2012, 3, 399-404.

40 K. A. Stoerzinger, L. Qiao, M. D. Biegalski and Y. Shao-Horn, J. Phys. Chem. Lett., 2014, 5, 1636-1641. 